\title{
Hybrid Repair \\ of Thoracoabdominal Aortic \\ Aneurysm with Rerouting of Visceral Arteries
}

\author{
Luca Apruzzi, Vincenzo Ardita, Andrea Melloni, \\ Yamume Tshomba, and Roberto Chiesa
}

\subsection{Introduction}

The treatment of thoracoabdominal aortic aneurysms (TAAA) is currently the most challenging operation for vascular and cardiovascular surgeons. In most cases, conventional open repair of TAAA represents the best treatment for patients deemed fit for surgery.

In the last few decades, technical advances in surgery, anesthesiology, and intensive care have improved clinical outcomes of TAAA open repair with 30-day mortality of less than $10 \%$ in selected series [1]. In larger series of patients, these results are not duplicated with overall mortality from 20 to $25 \%$, even higher in subgroups of older patients [2]. Apart from mortality,

\footnotetext{
L. Apruzzi $(\bowtie) \cdot$ V. Ardita $\cdot$ A. Melloni Scientific Institute H. San Raffaele, Vita-Salute University School of Medicine, Milan, Italy e-mail: apruzzi.luca@hsr.it; ardita.vincenzo@hsr.it; melloni.andrea@hsr.it

Y. Tshomba

Unit of Vascular Surgery, Fondazione Policlinico Universitario A. Gemelli IRCCS, Università Cattolica del Sacro Cuore, Rome, Italy

Unit of Vascular Surgery, San Raffaele Scientific Institute, Vita-Salute University, Milan, Italy e-mail: yamume.tshomba@unicatt.it

R. Chiesa

Unit of Vascular Surgery, San Raffaele Scientific Institute, Vita-Salute University, Milan, Italy e-mail: chiesa.roberto@hsr.it
}

neurological complications, in particular represented by spinal cord ischemia, remain the critical issue for the outcome of patient treated with open repair. Thus, in order to treat that proportion of patients with severe comorbidities or with prior aortic surgery, a less-invasive approach is needed. Hybrid TAAA treatment consists of the debranching of aortic collaterals and the exclusion of aortic aneurysms with a straight aortic endograft.

\subsection{Surgical Procedure}

Hybrid TAAA repair consists in a two-staged procedure: the first is the open visceral and renal debranching and the second is the aortic endografting.

The first stage is usually achieved through midline laparotomy; in fact, in the absence of prior abdominal surgery or laparotomy, this approach allows a contemporary exposure of the proximal segment of visceral and renal arteries as well as the iliac arteries.

Celiac trunk (CT) isolation can be achieved in the omental bursa above the pancreas (Fig. 21.1).

CT revascularization can be accomplished via an end-to-side bypass to the common hepatic artery. By revascularizing the hepatic artery but ligating the celiac trunk, the left gastric and splenic arteries can continue to be perfused by retrograde flow from the proximal hepatic artery. In the case 


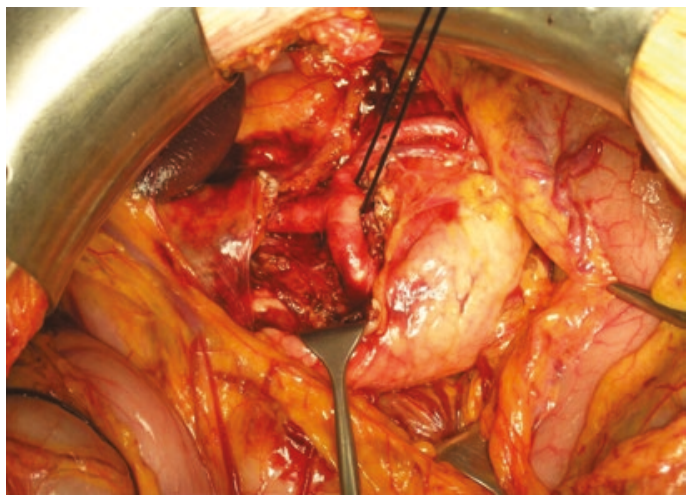

Fig. 21.1 Intraoperative image showing celiac trunk exposure. The greater omentum is divided and the stomach moved down and to the left side, exposing the pancreas. The origin of celiac trunk (under a vessel loop) is just behind the pancreas which can be carefully moved down to gain enough space for the anastomosis

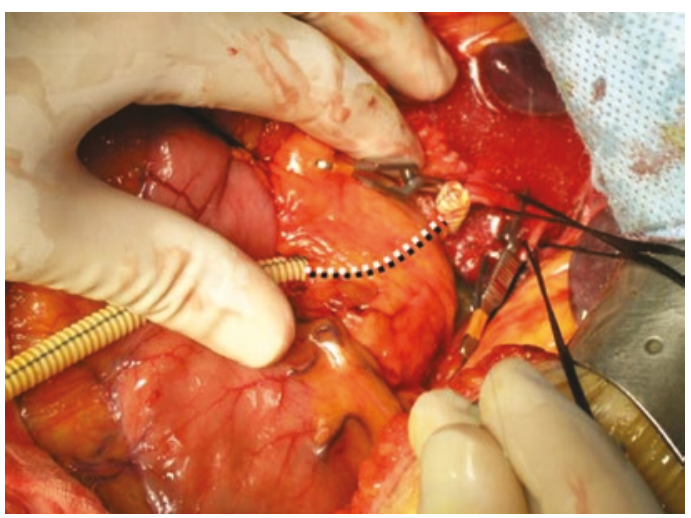

Fig. 21.2 The prosthetic branch to celiac trunk can be routed behind the pancreas as shown by the dashed line

of anastomosis directly to the celiac trunk, an end-to-end anastomosis is usually preferred in a position which allows the vessel to be ligated after completion of the bypass. The bypass can be routed in retropancreatic position, but antepancreatic routing especially in cases of anastomosis on the common hepatic artery can avoid the risk of pancreatic damages due to tunneling (Fig. 21.2).

An end-to-end anastomosis is usually preferred for the superior mesenteric artery (SMA) in the omental bursa behind the pancreas. The SMA can be easily identified at the base of the transverse mesocolon and vascularized by an end-to-side anastomosis with a ligation just proximally to the graft (Figs. 21.3 and 21.4).
Both renal arteries can be easily isolated proximally as they branch from the abdominal aorta, and also in this case, an end-to-end bypass is preferred.

In cases in which a distal isolation of the right renal artery is needed, it can be achieved with Kocher's maneuver consisting in medial mobilization of the duodenum (Fig. 21.5).

During visceral reconstruction, organ ischemia can be managed using Pruitt-Inahara catheters positioned in vessels' ostia in order to permit contemporary clamping and perfusion (Fig. 21.6).

The visceral arteries can be perfused with cold perfusion (Ringer's solution $4{ }^{\circ} \mathrm{C}$ ); in cases requiring a longer renal clamping, a renal perfusion with a bolus of $4{ }^{\circ} \mathrm{C} 300 \mathrm{~mL}$ of lactated Ringer's solution supplemented with mannitol $18 \%$ $(70 \mathrm{~mL})$ and 6-methylprednisolone $(500 \mathrm{mg})$ or Custodiol ${ }^{\circledR}$ solution can be used.

In all reconstruction the grafted vessels are dissected over adequate distances to allow for secure management and ligation. Prosthetic bypass grafts are used for revascularization. Commercially available grafts designed for abdominal debranching can be used, but in addition, different custommade configurations for visceral bypasses can be obtained with a variety of straight or bifurcated Dacron or e-PTFE prostheses.

In most cases, bypasses are constructed in a retrograde fashion. The choice of inflow site is based on the TAAA extension, the presence of prior aortoiliac surgery, and the quality of the walls of native vessels. In fact, the proximal anastomosis is usually placed on the common iliac arteries, but the infrarenal aorta, in the absence of aneurysms, can be used as inflow site. In cases of infrarenal and iliac aneurysms, it is possible to replace infrarenal aorta with a tube or bifurcated prosthesis and then use the graft as the inflow site for visceral bypasses (Fig. 21.7).

In these cases, attention must be taken to leave enough native aorta or graft to ensure a good distal landing zone to place the planned endograft. Rarely, in selected cases, the thoracic aorta can be used as inflow site for visceral debranching constructing the bypasses in anterograde fashion (Fig. 21.8).

Target vessels can be revascularized individually or in a series with jump grafts. Finally, in the majority of cases, the proximal stump of the target arteries was ligated to avoid retrograde perfusion of the aneurysm. 

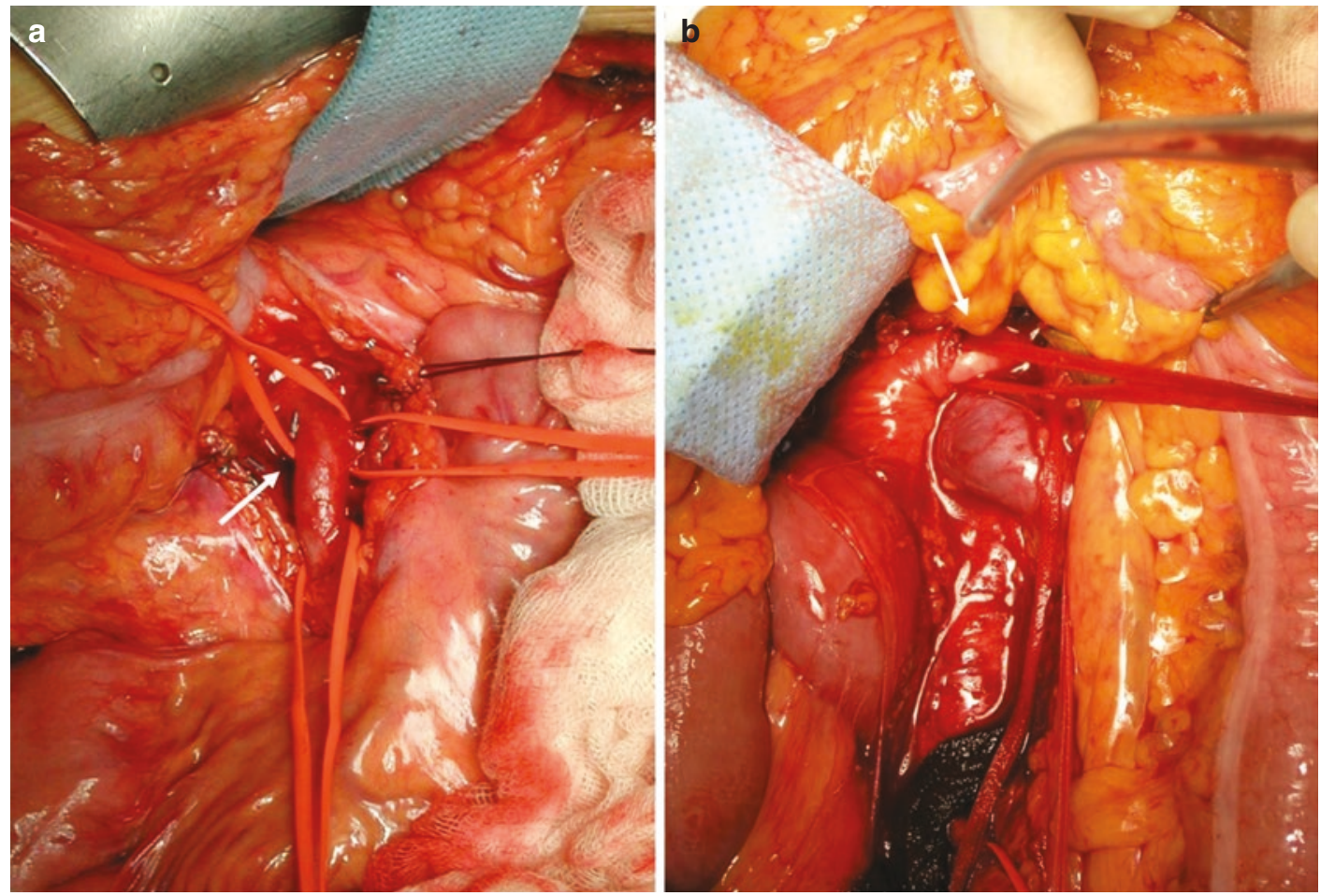

Fig. 21.3 Vascular access for the superior mesenteric artery (white arrow) can be achieved via the omental bursa at its origin from the aorta (A) or at the base of the mesocolon just cranially to the left renal vein

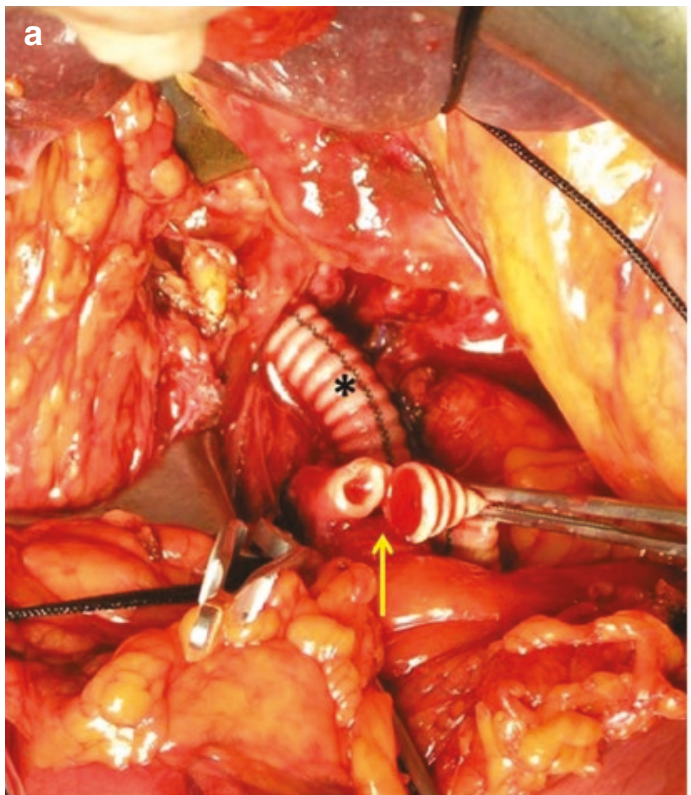

Fig. 21.4 Intraoperative image showing distal SMA separated from its origin and is exposed nearby the graft (yellow arrow) to perform the distal end-to-end anastomosis.

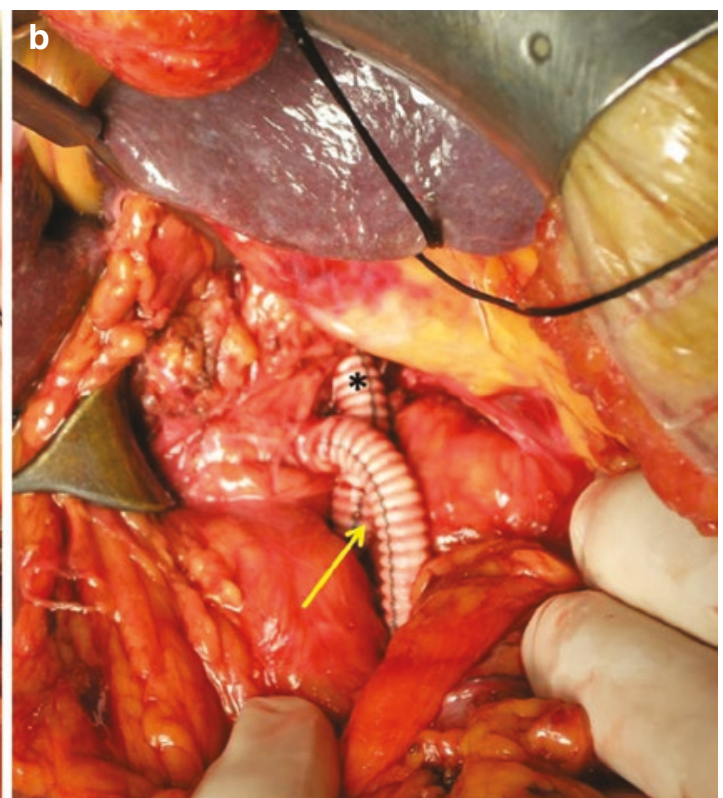

After the completion of the suture, the graft to the SMA is positioned in the omental bursa nearby the graft to the celiac trunk (asterisk) 
Recently, the use of sutureless anastomosis techniques has been proposed for the reconstruction of visceral vessels (Chap. 22). The VORTEC (Viabahn Open Revascularization TEChnique) [3] is a less-invasive prosthetic graft anastomotic technique that uses self-expanding stent grafts

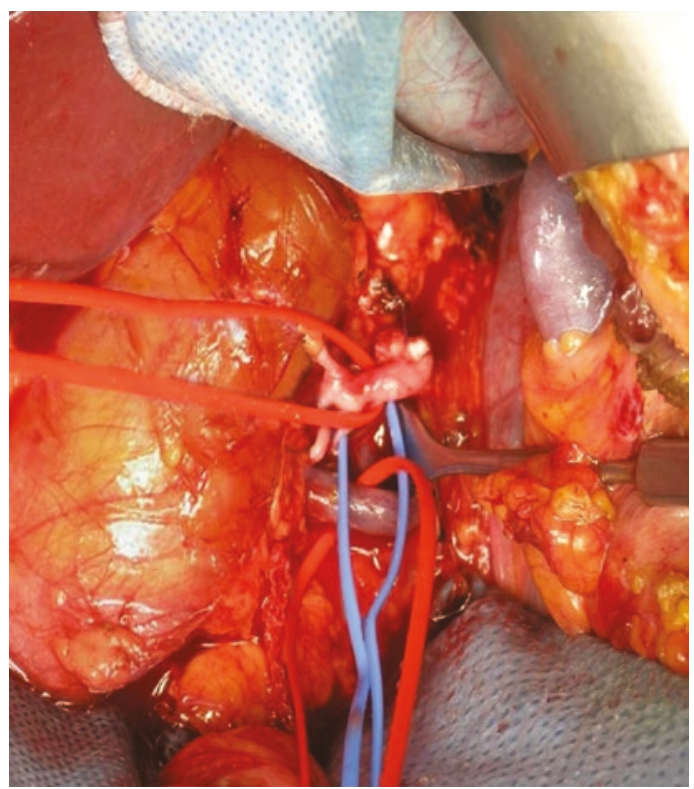

Fig. 21.5 Intraoperative image showing complete skeletonization of the renal hilum with renal vessels suspended by red vessel loops. By a surgical dissection of the duodenum, it can be reflected to the left (Kocher's maneuver) giving access to distal right renal artery

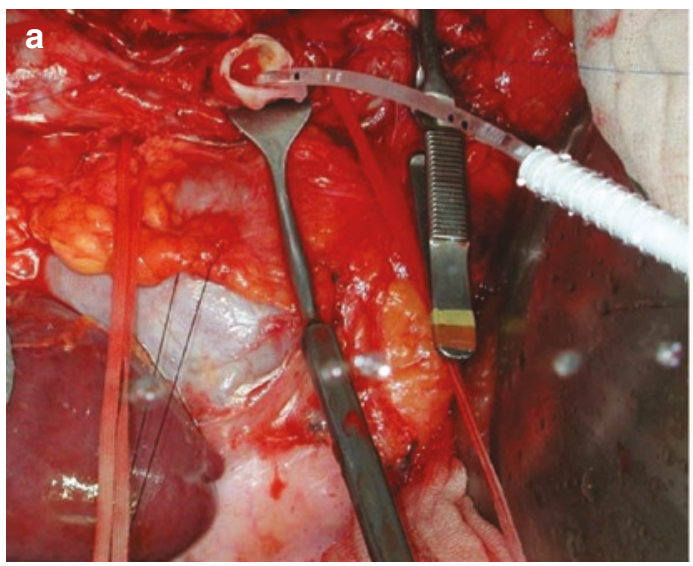

Fig. 21.6 Intraoperative images of a right renal artery reconstruction. A Pruitt-Inahara catheter is positioned into the artery to achieve endo-clamping and contemporary
(W.L. Gore \& Associates, Inc., Flagstaff, AZ, USA) that are "telescoped" into aortic vessels, and the end of the stent graft outside of the target artery is sutured end to side directly with the inflow vessel. The main morphological indications to perform the VORTEC are diameter of the renal or superior mesenteric artery $>4 \mathrm{~mm}$, distal landing zone of $>1 \mathrm{~cm}$, and absence of relevant branches of the artery in the landing zone.

The use of Gore Hybrid Vascular Graft (W.L. Gore \& Associates, Inc., Flagstaff, AZ, USA) may represent a significant advantage in reducing vessel dissection and organ ischemia during revascularization [4]. As described for the VORTEC, the use of this graft in most cases is limited to renal arteries (Fig. 21.9) which usually have enough space for the deployment of the covered stent before the origin of its first side branches.

After the completion of renovisceral bypasses, when possible, they should be covered with retroperitoneum or omental flaps to avoid direct contact with the bowel.

The second stage of the hybrid repair consists of aortic endografting to exclude the aneurysm. It can be performed concomitantly or in a staged fashion. A staged approach allows the patient to recover from the surgical stress of laparotomy and from visceral and renal debranching, but on the other hand, the waiting for a subsequent aortic endograft leaves the patient at risk of interval rupture [5].

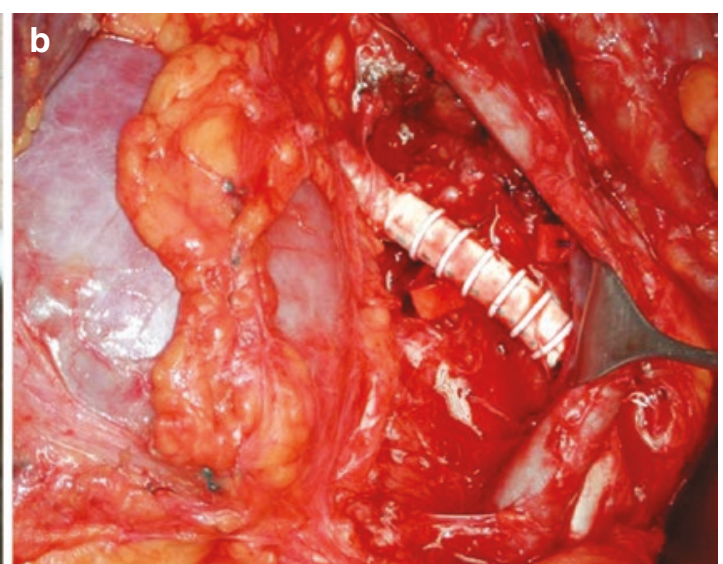

perfusion with cold solution (a). In this case the ringed e-PTFE graft is routed behind the inferior cava vein (b) which in the image is moved left under the retractor 

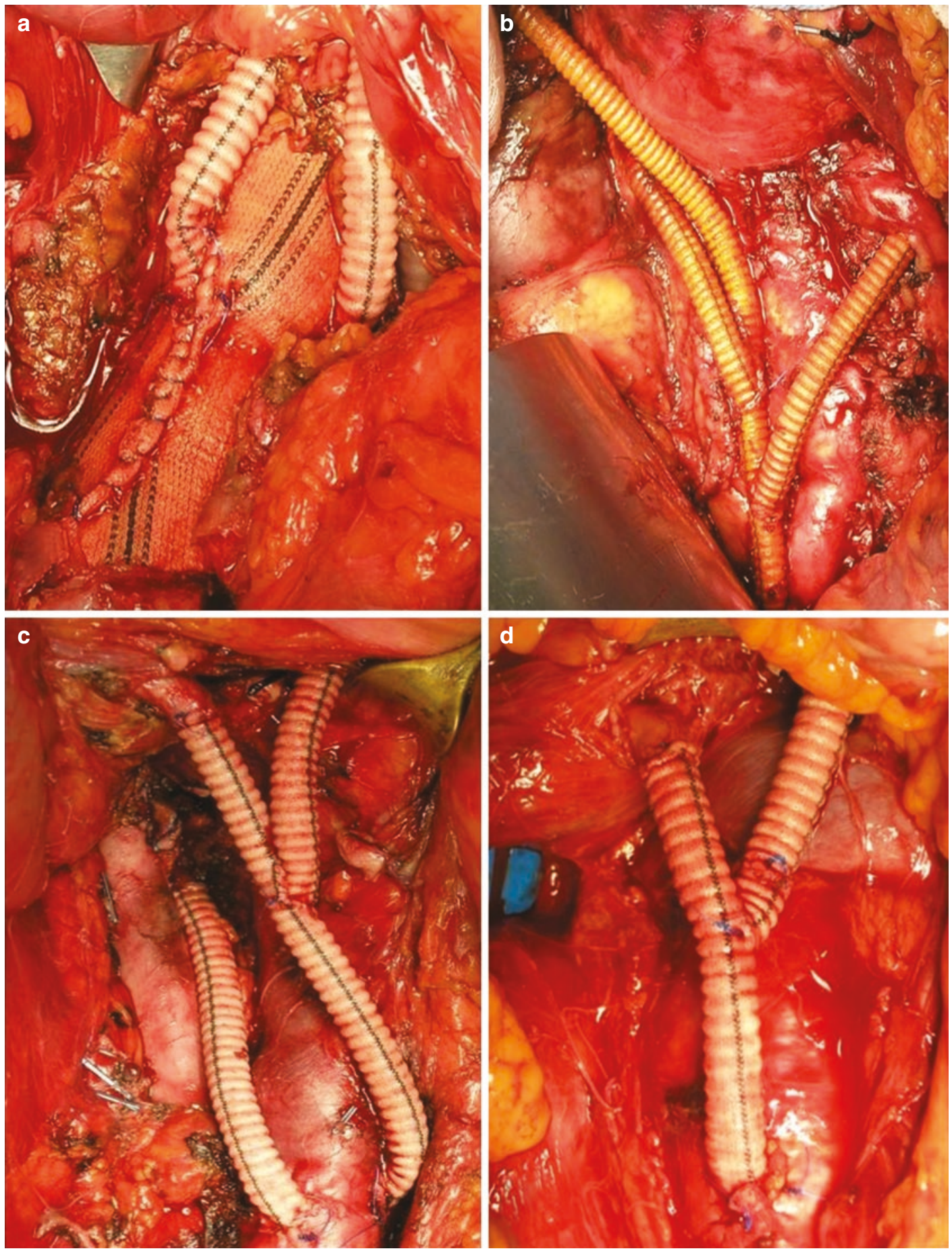

Fig. 21.7 Intraoperative images of different graft configurations for visceral and renal revascularization. (a) After infrarenal aortic replacement, aortic graft is used as inflow site for visceral bypasses. In absence of aneurysms, the common iliac artery (b) or infrarenal aorta $(\mathbf{c}, \mathbf{d})$ could be an option to seat the proximal anastomosis of bypasses. Visceral and renal vessels can be vascularized individually (a) or in series with bifurcated grafts (b-d) 
Fig. 21.8 An anatomical drawing and a CT scan 3D atypical debranching for visceral and renal arteries. In this case, the inflow site used for bypasses is the ascending aorta with the prosthesis routed through the diaphragm reconstruction of an

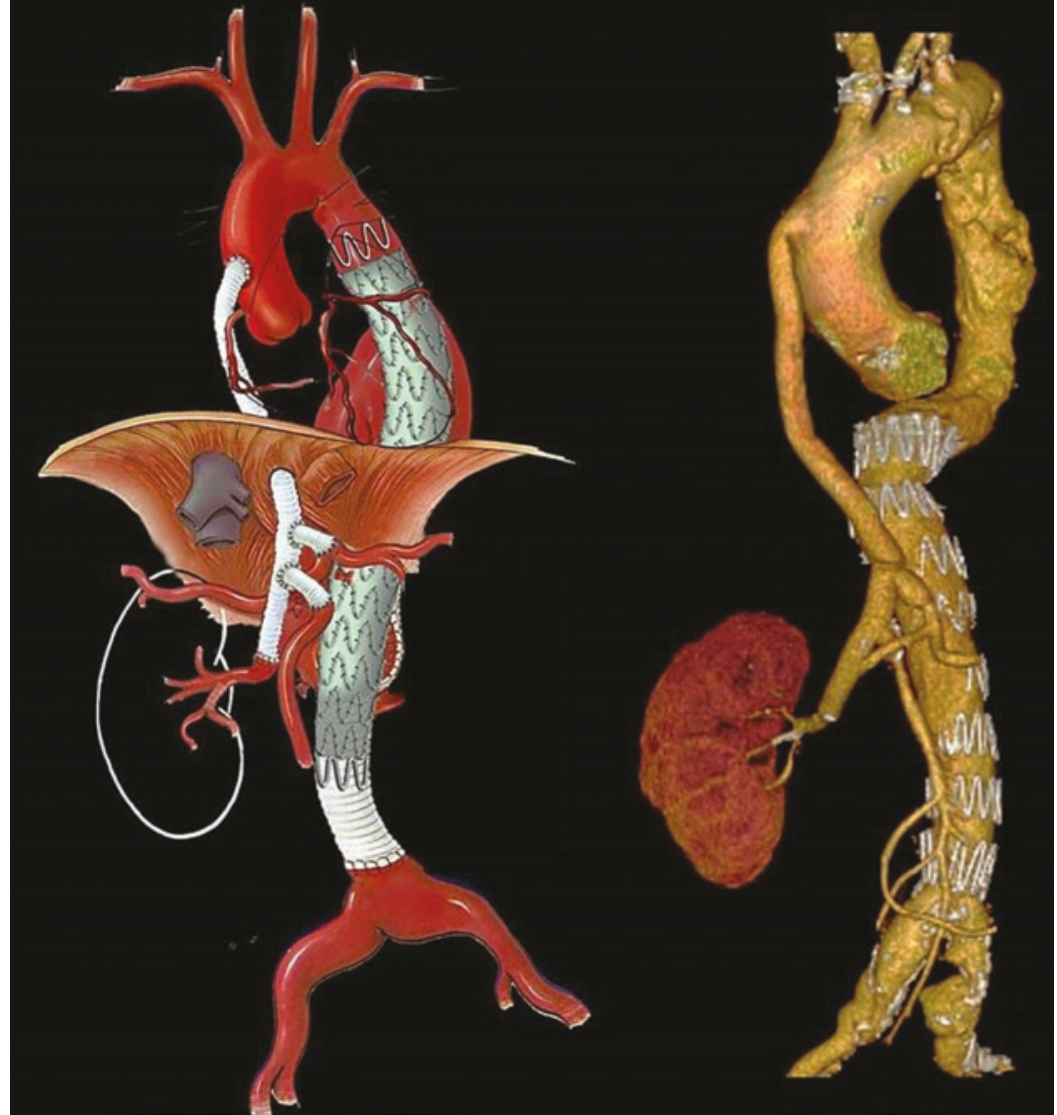

Fig. 21.9 A postoperative CT angiography showing reconstruction of the right renal artery with Gore Hybrid Vascular Graft. In the right yellow box, the reconstructed renal artery is marked, compared with the left yellow box which shows a sample of a Gore Hybrid Vascular Graft

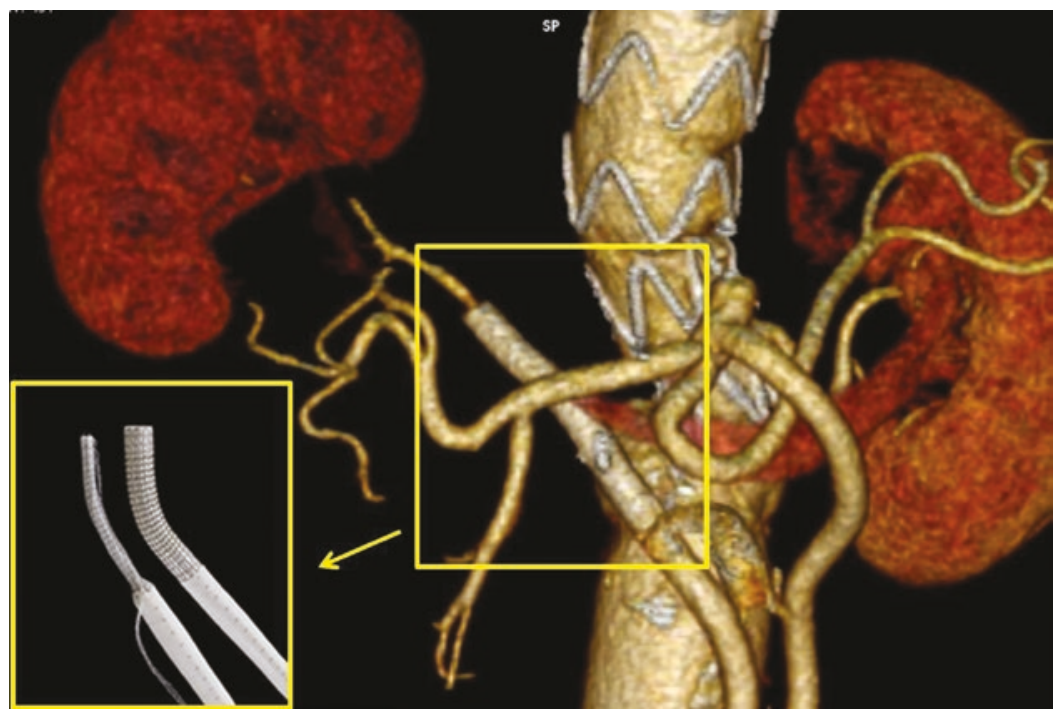




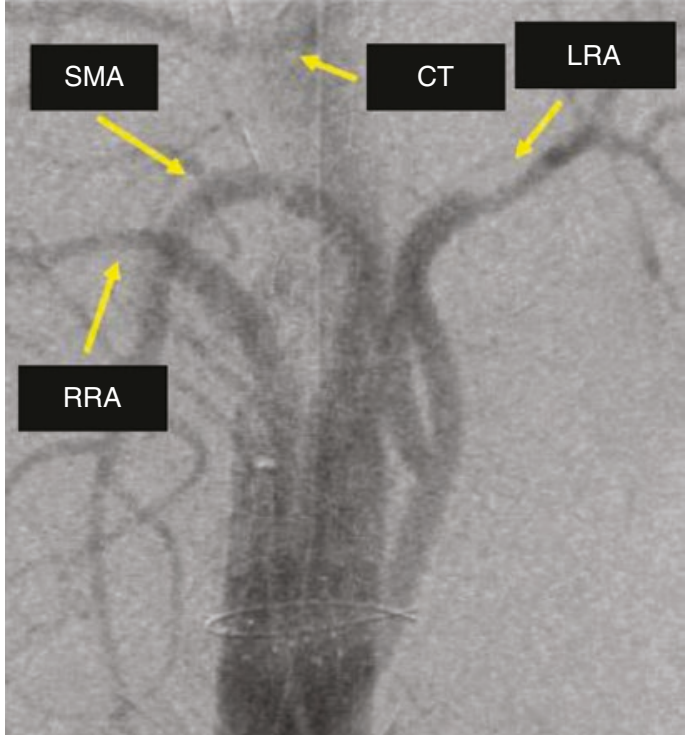

Fig. 21.10 An intraoperative angiography after deployment of the endograft showing the patency of visceral graft to the celiac trunk (CT), superior mesenteric artery (SMA), and left and right renal artery (LRA, RRA)

Different combinations of thoracic endografts can be used to achieve TAAA exclusion. A femoral approach, percutaneous or with a surgical exposure of the artery, is usually preferred. In selected cases, iliac artery or a prosthetic conduit attached or pre-sewn to aortic vascular graft can be used as an access site for the endograft. The choice of endovascular device should be based on surgeon experience and preference and patient anatomy. Completion angiography must always be performed after deploying the graft to ensure the effective aneurysm exclusion and to check the patency of visceral bypasses (Fig. 21.10). Due to the extension of aortic coverage, especially for Crawford's type I to III TAAA, spinal drain and somatosensory evoked potential (SSEP) monitoring might be used for spinal cord protection.

\subsection{Clinical Outcome}

The hybrid approach to TAAA should have the theoretic advantage to reduce major complications. The possibility to treat a complex aortic pathology with a standard median laparotomy and endovascular repair remains appealing. In scientific literature, many studies have been published reporting ambiguous results with a big heterogeneity in terms of mortality and morbidities (Table 21.1).

In 2012 a meta-analysis published by Moulakakis et al. [27] confirmed such controversial outcomes. The authors analyzed 14 studies with a total of 528 patients and mean follow-up time of 34.2 months. The 30-day mortality rate was $14.3 \%$; the symptomatic spinal cord ischemia, irreversible paraplegia, permanent renal failure, and mesenteric ischemia were $7 \%, 4.4 \%, 7 \%$, and $4.5 \%$, respectively. Pooled estimates for primary technical success and visceral graft patency were $95.4 \%$ and $96.5 \%$, respectively. Furthermore, the authors reported that better results with lower complication rates are achieved in high-volume aortic centers.

\subsection{Discussion}

There are currently three options for the treatment of TAAA. Open surgical TAAA repair (Chap. 19) is demonstrated to represent a durable option [28, 29], but in older patients with significant comorbidities, it may not be tolerated for the exposure of two cavities, left heart bypass and aortic crossclamping. The search for less stressful procedures has been proposed to treat high-risk populations who are not deemed fit for open surgery. Total endovascular approaches with branched or fenestrated endografts (Chap. 24) have been described as very promising options [30] but are not widely available and require a degree of endovascular skills that not all centers possess. Furthermore, in some cases, the waiting time for the production of custom-made devices may expose patients to the risk of aneurysm rupture.

The hybrid TAAA repair, first described by Quinones-Baldrich in 1999 [31], is associated to less surgical stress with a technique that can even be applied in patients with several limitations. By avoiding thoracotomy, hybrid repair may be considered in patients with previous thoracic surgery. In fact, a redo left-side thoracotomy in a "frozen chest" could be technically complicated, and 
Table 21.1 Published studies reporting TAAA experience with at least more than five patients (ND, not described or not reported)

\begin{tabular}{l|l|l|l|l|l|l}
\hline Author & $n$ & $\begin{array}{l}\text { 30-day } \\
\text { mortality (\%) }\end{array}$ & Paraplegia (\%) & $\begin{array}{l}\text { Graft patency } \\
\text { rate }(\%)\end{array}$ & Endoleaks (\%) & $\begin{array}{l}\text { Mean follow-up } \\
\text { (months) }\end{array}$ \\
\hline Fulton et al. [6] & 10 & 0 & 0 & 100 & 10 & 8.7 \\
\hline Resch et al. [7] & 13 & 23 & 15 & ND & ND & ND \\
\hline Zhou et al. [8] & 31 & 3.2 & 0 & 98 & 6 & 16 \\
\hline Gawenda et al. [9] & 6 & 0 & 0 & 94.7 & 0 & ND \\
\hline Lee et al. [10] & 17 & 24 & 0 & 96 & 12 & 8 \\
\hline Van de Mortel et al. [11] & 16 & 31 & 0 & 95 & 13 & 13 \\
\hline Böckler et al. [12] & 28 & 14.3 & 4 & 86 & 17.8 & 22 \\
\hline Quinones-Baldrich et al. [13] & 20 & 0 & 6.6 & 100 & 30 & 17 \\
\hline Donas et al. [14] & 58 & 8.6 & 3.4 & 97 & 17 & 22 \\
\hline Biasi et al. [15] & 18 & 16.7 & 5.6 & 98.1 & 38.9 & 23 \\
\hline Drinkwater et al. [16] & 107 & 15 & 8.4 & 87 & 33 & ND \\
\hline Patel et al. [17] & 23 & 17 & 4 & 90 & 23 & 6 \\
\hline Kabbani et al. [18] & 36 & 8.3 & 0 & 93 & 39 & 6 \\
\hline Muehling et al. [19] & 16 & 31.2 & 6.2 & ND & 37.5 & 12 \\
\hline Kuratani et al. [20] & 86 & 2.3 & 0 & 99 & 17 & 88 \\
\hline Wolf and Eckstein [21] & 20 & 10 & 10 & ND & 30 & 6 \\
\hline Smith et al. [22] & 24 & 12.5 & 8.3 & 99 & 95 & 12 \\
\hline Hughes et al. [23] & 58 & 9 & 4 & 93 & ND & 26 \\
\hline Tshomba et al. [24] & 52 & 14 & 119 & 79 & 3 & 24 \\
\hline Rossett et al. [25] & 76 & 34 & 13 & ND & 30 \\
\hline Massoni et al. [26] & 45 & 24 & & & 26 \\
\hline
\end{tabular}

aortic exposure in a scarred operatory field can increase both intraoperative complications such as bleeding and organ injuries and postoperative complications like respiratory failure $[32,33]$.

The choice of simultaneous or staged procedure is a debated issue. The one-stage strategy has the advantage to eliminate the risk of interoperative rupture [16] and in cases of inadequate femoral arteries can be an advantage to prompt availability of aortic or iliac access for the endograft deployment. In cases of staged procedure and unavailability of femoral access, a prosthetic conduit implanted on the abdominal aorta may be a solution. The staged approach offers the advantage of shortening the overall procedural time, thus reducing organ ischemic time and the risk of renal injury [4].

Postoperative renal failure remains a major complication after TAAA repair [5]. The hybrid approach does not eliminate the risk of renal injury that remains higher than $60 \%$, especially in patients treated with a single-staged intervention [34]. In fact, the combination of renal ischemia during debranching and the administration of contrast right after renal revascularization can significantly increase the risk of renal failure, especially in patients with preexisting lower renal function. The use of sutureless techniques or new graft configuration [3, 4] for the revascularization of renal arteries showed a reduction of renal injury after renal revascularization due to the shortening of surgical and ischemia time. Tshomba et al. [35] recently proposed the use of Custodiol ${ }^{\circledR}$ solution for renal artery perfusion during open TAAA repair, demonstrating a reduction of acute kidney injury and improving perioperative renal function compared with cool lactated Ringer's solution.

The problem of spinal cord ischemia (SCI) has not been eliminated by hybrid TAAA repair, due to the requirement of extensive coverage of thoracoabdominal aorta [36]. In fact, Gravereaux et al. [37] demonstrated a significant association between a longer stent graft length and the incidence of neurological symptoms. Of course, the avoidance of aortic cross-clamping could lead to a major intraoperative and postoperative hemodynamic stability with reduction of risk of SCI [38]. The use of simultaneous adjuncts such as PESS 

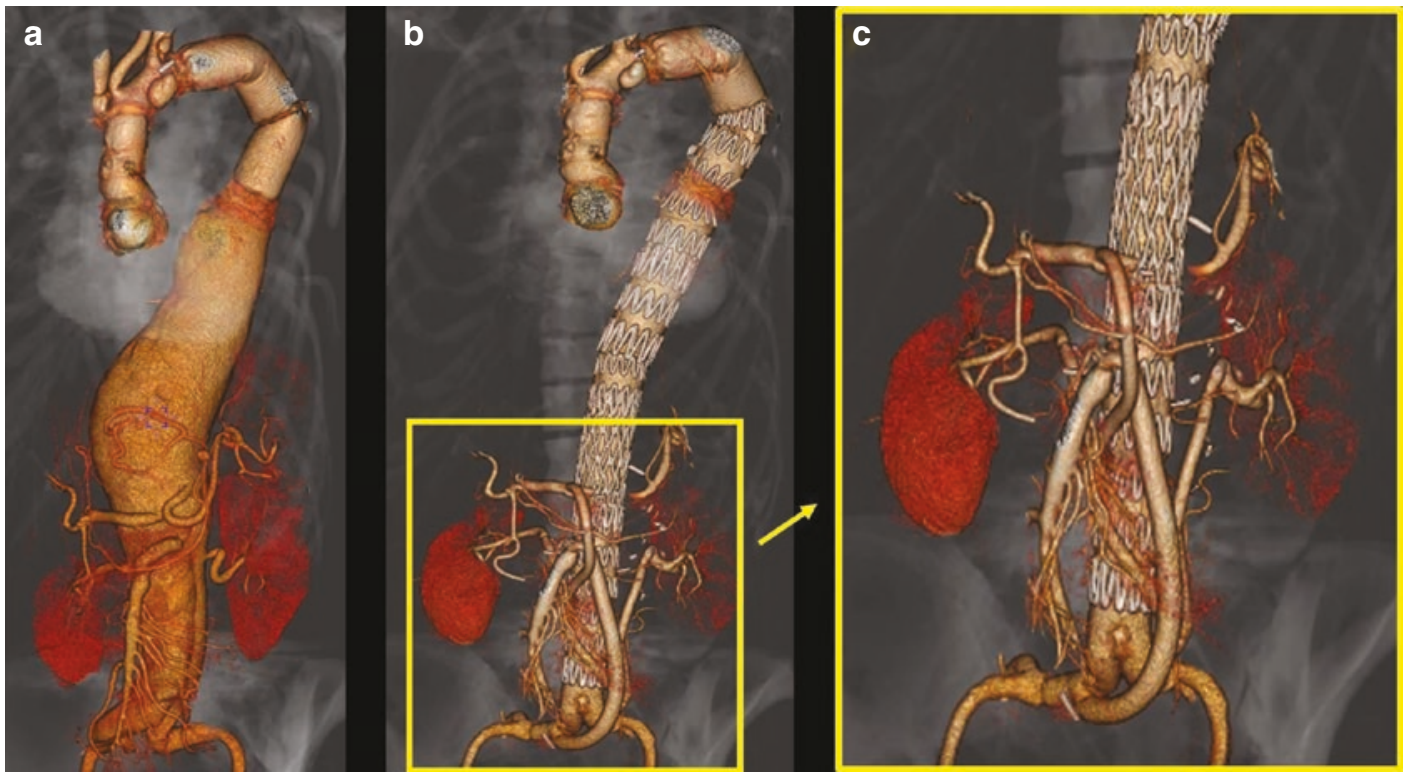

Fig. 21.11 Preoperative (a) and 1-year CT angiography (b) after a Crawford's type II TAAA hybrid repair. Note in the zoomed image (c) the aneurysm exclusion and patency of visceral and renal arteries after repair

and MES monitoring and cerebrospinal fluid drainage can reduce the incidence of SCI especially for Crawford's type II TAAA or in case of prior aortic repairs [39].

The patency and related complications of visceral bypasses are another matter of concern. Visceral graft occlusion may be the cause of devastating complications, such as pancreatitis and bowel ischemia. A safe routing of visceral graft must always be performed, as mentioned above, an antepancreatic routing of celiac trunk graft should be preferred in order to reduce pancreatic injuries. Therefore the risk of enteric erosion or fistulization must be monitored in the follow-up. A postoperative angiogram both in not-staged and in staged procedures can show technical defects of the anastomosis or visceral vessel dissection that can be promptly corrected. In particular for the SMA, vessel angulation can be a risk factor for a graft occlusion evidenced after bowel repositioning, kinked anastomosis, or twisted grafts can be corrected with a self-expandable stent.

A limitation of hybrid TAAA repair involves endoleaks probably secondary to aortic remodeling over time and long-segment endografts implanted for aneurysm exclusion [40]. In scientific literature, the incidence of endoleaks is variable in different series (Table 21.1) but is a matter of concern because it may expose patients to future reintervention and may leave them at risk of aneurysm rupture. Especially in cases of type Ia endoleak, the treatment may be challenging in cases of inadequate proximal landing zone nearby supra-aortic vessels.

A postoperative surveillance of patients, in particular for Crawford's type II TAAA, should be maintained with contrast CT scans at scheduled follow-up intervals of 1,6 , and 12 months and yearly thereafter, given to their risk for endoleak and for visceral graft occlusion (Fig. 21.11).

\subsection{Conclusion}

Open conventional repair represents the gold standard for the treatment of TAAA for patients considered fit for surgery. Hybrid repair for TAAA remains an appealing technique, but many issues about this approach remain unsolved such as the outcome of visceral bypasses, long-term durability of the endograft materials, and the fate of excluded aneurysm in terms of endoleaks. 
Complete abdominal aortic debranching and endovascular aneurysm exclusion remains a good option for selected elderly, high-risk patients in high-volume centers with expertise in management of visceral revascularization. Nowadays, fenestrated and branched endografts are developing as a less-invasive alternative for treating complex aortic aneurysms with good results.

The question of whether hybrid repair leads to improve outcomes compared to open or total endovascular repair still remains controversial, and larger study cohorts with longer follow-up are needed.

\section{References}

1. LeMaire SA, Price MD, Green SY, et al. Results of open thoracoabdominal aortic aneurysm repair. Ann Cardiothorac Surg. 2012;1(3):286-92. https://doi. org/10.3978/j.issn.2225-319X.2012.08.16.

2. Cowan JA Jr, Dimick JB, Henke PK, et al. Surgical treatment of intact thoracoabdominal aortic aneurysms in the United States: hospital and surgeon volumerelated outcomes. J Vasc Surg. 2003;37:1169-74.

3. Lachat M, Mayer D, Criado FJ, et al. New technique to facilitate renal revascularization with use of telescoping self-expanding stent grafts: VORTEC. Vascular. 2008;16:69-72.

4. Chiesa R, Kahlberg A, Mascia D, et al. Use of a novel hybrid vascular graft for sutureless revascularization of the renal arteries during open thoracoabdominal aortic aneurysm repair. J Vasc Surg. 2014;23(14):670-3.

5. Canaud L, Karthikesalingam A, Jackson D, et al. Clinical outcomes of single versus staged hybrid repair for thoracoabdominal aortic aneurysm. J Vasc Surg. 2013 Nov;58(5):1192-200.

6. Fulton JJ, Farber MA, Marston WA, et al. Endovascular stent-graft repair of pararenal and type IV thoracoabdominal aortic aneurysms with adjunctive visceral reconstruction. J Vasc Surg. 2005;41(2):191-8.

7. Resch TA, Greenberg RK, Lyden SP, et al. Combined staged procedures for the treatment of thoracoabdominal aneurysms. J Endovasc Ther. 2006;13:481-9.

8. Zhou W, Reardon M, Peden EK, et al. Hybrid approach to complex thoracic aortic aneurysms in high-risk patients: surgical challengers and clinical outcome. J Vasc Surg. 2006;44:688-93.

9. Gawenda M, Aleksic M, Heckenkamp J, et al. Hybrid-procedures for the treatment of thoracoabdominal aortic aneurysms and dissections. Eur J Vasc Endovasc Surg. 2007;33:71-7.

10. Lee WA, Brown MP, Martin TD, et al. Early results after staged hybrid repair of thoracoabdominal aortic aeurysms. J Am Coll Surg. 2007;205:420-31.
11. Van de Mortel RHW, Vahl AC, Balm R, et al. Collective experience with hybrid procedures for suprarenal and thoracoabdominal aneurysms. Vascular. 2008;16:140-6.

12. Böckler D, Kotelis D, Geisbusch P, et al. Hybrid procedures for thoracoabdominal aortic aneurysms and chronic aortic dissections - a single center experience in 28 patients. J Vasc Surg. 2008;47:724-32.

13. Quinones-Baldrich W, Jimenez JC, DeRubertis B, et al. Combined endovascular and surgical approach (CESA) to thoracoabdominal aortic pathology: a 10-year experience. J Vasc Surg. 2009;49:1125-34.

14. Donas KP, Lachat M, Rancic Z, et al. Early and mid-term outcome of a novel technique to simplify the hybrid procedures in the treatment of thoracoabdominal and pararenal aortic aneurysms. J Vasc Surg. 2009;50:1280-4.

15. Biasi L, Ali T, Loosemore T, et al. Hybrid repair of complex thoracoabdominal aortic aneurysms using applied endovascular strategies combined with visceral and renal revascularization. J Thorac Cardiovasc Surg. 2009;138:1331-8.

16. Drinkwather SL, Böckler D, Eckstein H, et al. The visceral hybrid repair of thoraco-abdominal aortic aneurysms - a collaborative approach. Eur J Vasc Endovasc Surg. 2009;38:578-85.

17. Patel R, Conrad MF, Paruchuri V, et al. Thoracoabdominal aneurysm repair: hybrid versus open repair. J Vasc Surg. 2009;50:15-22.

18. Kabbani LS, Criado E, Upchurch JR, et al. Hybrid repair of aortic aneurysms involving the visceral and renal vessels. Ann Vasc Surg. 2010;24:219-24.

19. Muehling BM, Bischoff G, Schelzig H, et al. Hybrid procedures for complex thoracoabdominal aortic aneurysms: early results and secondary interventions. Vasc Endovasc Surg. 2010;44:110-5.

20. Kuratani T, Kato M, Shirakawa Y, et al. Long-term results of hybrid endovascular repair for thoracoabdominal aortic aneurysms. Eur J Cardiotorac Surg. 2010;38:299-304.

21. Wolf O, Eckstein HH. Combined open and endovascular treatment of thoracoabdominal aneurysms and secondary expanding aortic dissections: early and mid-term results from a single center series. Ann Vasc Surg. 2010;24:167-77.

22. Smith TA, Gatens S, Andres M, et al. Hybrid repair of thoracoabdominal aortic aneurysms involving the visceral vessels: comparative analysis between number of vessels reconstructed, conduit, and gender. Ann Vasc Surg. 2011;25:64-70.

23. Hughes GC, Andersen ND, Hanna JM, et al. Thoracoabdominal aortic aneurysm: hybrid repair outcomes. Ann Cartiothorac Surg. 2012;1:311-9.

24. Tshomba Y, Melissano G, Logaldo D, et al. Clinical outcomes of hybrid repair for thoracoabdominal aortic aneurysms. Ann Cardiotorac Surg. 2012;1: 293-303.

25. Rosset E, Ben Ahmed S, Galvaing G, et al. Editor's choice - Hybrid treatment of thoracic, thoracoabdominal, and abdominal aortic aneurysms: a multi- 
center retrospective study. Eur J Vasc Endovasc Surg. 2014;47:470-8.

26. Massoni CB, Geisbsoch P, Gallitto E, et al. Follow-up outcomes of hybrid procedures for thoracoabdominal aortic pathologies with special focus on graft patency and late mortality. J Vasc Surg. 2014;59:1265-73.

27. Moulakakis KG, Mylonas SN, Antonopoulos CN, et al. Combined open and endovascular treatment of thoracoabdominal aortic pathologies: a systematic review and meta-analysis. Ann Cardiothorac Surg. 2012;1(3):267-76.

28. Wong DR, Parenti JL, Green SY, et al. Open repair of thoracoabdominal aortic aneurysm in the modern surgical era: contemporary outcomes in 509 patients. J Am Coll Surg. 2011;212:569-79. discussion: 579-81.

29. Coselli JB, LeMaire SA. Open surgical repair of 2286 thoracoabdominal aortic aneurysms. Ann Thorac Surg. 2007;83:S862-4. discussion: S890-2.

30. Clough RE, Modarai B, Bell RE, et al. Total endovascular repair of thoracoabdominal aortic aneurysms. Eur J Vasc Endovasc Surg. 2012;43:262-7.

31. Quiñones-Baldrich WJ, Panetta TF, Vescera CL, et al. Repair of type IV thoracoabdominal aneurysm with a combined endovascular and surgical approach. J Vasc Surg. 1999;30(3):555-60.

32. Kawaharada N, Morishita K, Fukada J, et al. Thoracoabdominal aortic aneurysm repair through redo left-sided thoracotomy. Ann Thorac Surg. 2004;77:1304-8.

33. Menard MT, Nguyen LL, Chan RK, et al. Thoracovisceral segment aneurysm repair after previ- ous infrarenal abdominal aortic aneurysm surgery. J Vasc Surg. 2004;39:1163-70.

34. Lin PH, Kougias P, Bechara CF, et al. Clinical outcome of staged versus combined treatment approach of hybrid repair of thoracoabdominal aortic aneurysm with visceral vessel debranching and aortic endograft exclusion. Perspect Vasc Surg Endovasc Ther. 2012;24(1):5-13.

35. Tshomba Y, Kahlberg A, Melissano G, et al. Comparison of renal perfusion solutions during thoracoabdominal aortic aneurysm repair. J Vasc Surg. 2016;59:623-33.

36. Dias NV, Sonesson B, Kristmundsson T, et al. Shortterm outcome of spinal cord ischemia after endovascular repair of thoracoabdominal aortic aneurysms. Eur J Vasc Endovasc Surg. 2015;49:403-9.

37. Gravereaux EC, Faries PL, Burks JA, et al. Risk of spinal cord ischemia after endograft repair of thoracic aortic aneurysms. J Vasc Surg. 2001;34:997-1003.

38. Chiesa R, Melissano G, Marrocco-Trischitta MM, et al. Spinal cord ischemia after elective stentgraft repair of the thoracic aorta. J Vasc Surg. 2005;42(1):11-7.

39. Chiesa R, Tshomba Y, Melissano G, et al. Hybrid approach to thoracoabdominal aortic aneurysms in patients with prior aortic surgery. J Vasc Surg. 2007;45:1128-35.

40. Benrashid E, Wang H, Andersen ND, et al. Complementary roles of open and hybrid approaches to thoracoabdominal aortic aneurysm repair. J Vasc Surg. 2016;64:1228-38. 